Scientific Electronic Archives

Issue ID: Sci. Elec. Arch. Vol. 15 (2)

February 2022

DOI: http://dx.doi.org/10.36560/15220221511

Article link: https://sea.ufr.edu.br/SEA/article/view/1511

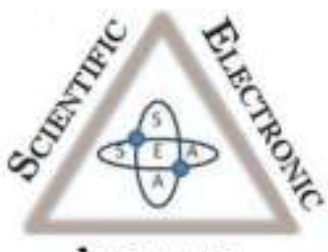

Archives

ISSN 2316-9281

\title{
Produção de biogás a partir de resíduos orgânicos: uma revisão
}

\section{Biogás production from organic waste: a review}

\author{
Corresponding author \\ Ana Luiza de Sousa \\ Instituto Federal de Educação, Ciência e Tecnologia de São Paulo, Câmpus Matão \\ sousa.luizaa@gmail.com \\ Márcia Luzia Rizzatto \\ Instituto Federal de Educação, Ciência e Tecnologia de São Paulo, Câmpus Matão
}

\begin{abstract}
Resumo. As mudanças climáticas que têm ocorrido têm levado à busca por alternativas de energias renováveis, visto que os combustíveis fósseis tem causado problemas ambientais, além da variabilidade de preços e a tendência de diminuição da oferta. Dessa forma, o biogás tem se tornado uma alternativa interessante para a produção de energia renovável e apresenta potencial de crescimento exponencial. Diante disso, esse artigo de revisão tratou da contextualização e análise do uso do biogás como fonte de energia, a partir de resíduos orgânicos. O processo de digestão anaeróbia pode ser uma alternativa ambiental viável para o tratamento de resíduos orgânicos, produzindo biogás e se tornando uma fonte de energia renovável. Entretanto, é um processo que exige condições específicas por envolver um sistema microbiológico, mas, se as condições operacionais forem otimizadas, faz com que o processo seja eficiente, como mostra os estudos apresentados.
\end{abstract}

Palavras-chaves Energia renovável, fontes alternativas, agroindústria.

Abstract. The climate changes that have taken place have led to the search for renewable energy alternatives, as fossil fuels have caused environmental problems, in addition to price variability and the tendency to decrease supply. Thus, biogas has become an interesting alternative for the production of renewable energy and has an exponential growth potential. Therefore, this review article dealt with the contextualization and analysis of the use of biogas as an energy source, from organic waste. The anaerobic digestion process can be a viable environmental alternative for the treatment of organic waste, producing biogas and becoming a renewable energy source. However, it is a process that requires specific conditions as it involves a microbiological system, but if the operating conditions are optimized, it makes the process efficient, based on the studies presented.

Keywords: Renewable energy, alternative sources, agribusiness.

\section{Contextualização e análise}

As mudanças climáticas são definidas como modificações no estado do clima da Terra que avançam por um grande período de tempo. Tais mudanças, observadas em toda a história do planeta, podem ter origem natural ou antrópica e se constituem em uma grande ameaça à biodiversidade e são consideradas um dos principais problemas ambientais do século XXI (Santos, 2021).

Segundo o Painel Intergovernamental sobre Mudanças Climáticas, o termo de alterações climáticas também pode ser utilizado para designar as mudanças climáticas, as quais se referem a uma modificação no estado do clima que pode ser identificada, com 0 auxílio da estatística, por exemplo, através de alterações na média e/ou na variabilidade das suas propriedades e que perduram durante um grande período de tempo, podendo atingir décadas ou mais (Carvalho et al., 2011).

As alterações climáticas podem ser ocasionadas naturalmente, como por exemplo os longos períodos de atividades dos vulcões, as alterações na inclinação do eixo Terra, entre outros. Contudo, também existe as alterações ocasionadas pelo homem, que tem acontecido de maneira cada vez mais intensa, agravando a situação climática, sobretudo após a Revolução Industrial (Santos, 2021).

Assim, as ações decorrentes da sociedade humana, tais como a geração de energia, a atividade de produção agrícola e a urbanização tem 
aumentado, ao longo dos anos, a concentração de gases na atmosfera que causam o efeito estufa, levando ao aumento na absorção de calor (Conceição et al., 2015).

A predominância dos combustíveis fósseis passa, cada vez mais, por obstáculos como a volatilidade de preços e a tendência de médio e longo prazo de diminuição na oferta, além dos problemas ambientais. Diante disso, a luta contra as mudanças climáticas tem se tornado um desafio cada vez maior, e isso tem levado à adoção crescente de fontes de energia renovável (Milanez et al, 2018), tornando cada vez mais significativa a busca por fontes renováveis de energia, como uma opção sustentável às oriundas do petróleo (Gallo et al., 2014; Vásquez et al., 2014).

A mudança desse recurso não renovável apresenta como vantagens a baixa de preços desses combustíveis e a redução de emissão de gases responsáveis pelo efeito estufa (Cypriano, 2015).

Em 2020, as fontes de energias renováveis foram responsáveis por $48,4 \%$ da energia consumida no Brasil, enquanto que $51,6 \%$ de fontes não renováveis. A Figura 1 mostra a repartição da Oferta Interna de Energia (OIE).

Quanto à repartição de oferta de "Outras renováveis", ocorre em 7 categorias de fontes de energias renováveis, nas quais as maiores participações ocorreram por parte da lixívia, biodiesel e energia eólica, cujos valores somados correspondem a mais de $80 \%$. Entretanto, vale destacar a participação do biogás, com 1,4\% (Figura 2), mas que demonstrou aumento em relação ao ano de 2019 (Figura 3).

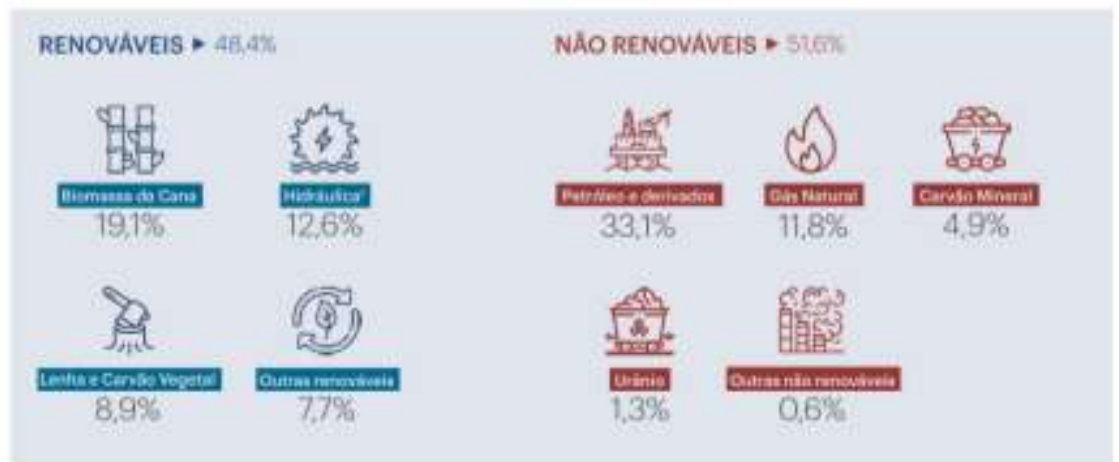

Figura 1. Repartição da Oferta Interna de Energia (OIE) em 2020. Fonte: BEN, 2021.

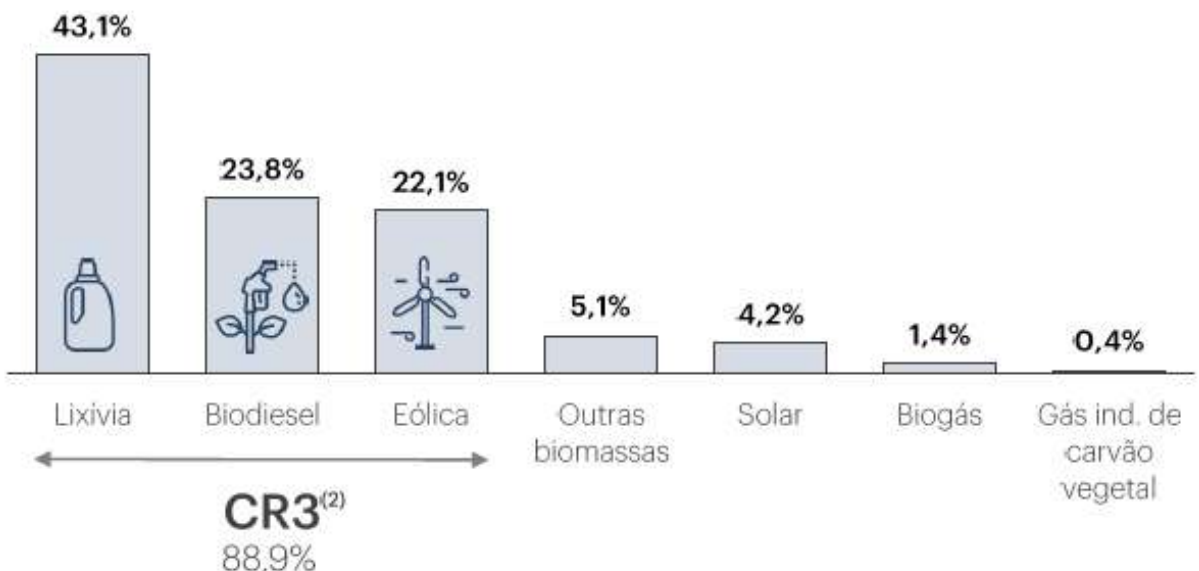

Figura 2. Repartição da oferta de "outras renováveis". (¿) Índice de Razão de Concentração CR3 é a representatividade das três maiores fontes juntas. Fonte: BEN, 2021. 


\begin{tabular}{|l|c|c|c|}
\hline Outras renováveis $\left(\mathbf{1 0}^{\mathbf{3}}\right.$ tep) & $\mathbf{2 0 1 9}$ & $\mathbf{2 0 2 0}$ & $\mathbf{4} \mathbf{2 0 / 1 9}$ \\
\hline Lixivia & 8.948 & 9.576 & $7,0 \%$ \\
\hline Biodiesel & 4.878 & 5.300 & $8,6 \%$ \\
\hline Eólica & 4.815 & 4.906 & $1,9 \%$ \\
\hline Outras biomassas' & 1.149 & 1.139 & $-0,9 \%$ \\
\hline Solar & 572 & 924 & $61,5 \%$ \\
\hline Biogás & 269 & 311 & $15,7 \%$ \\
\hline Gás industrial de carvão vegetal & 81 & 85 & $4,3 \%$ \\
\hline Total & 20.712 & 22.241 & $\mathbf{7 , 4} \%$ \\
\hline
\end{tabular}

Figura 3. Comparativo dos anos 2019 e 2020 quanto à Repartição da oferta de "outras renováveis". ' Inclui casca de arroz, capim-elefante e óleos vegetais. Fonte: BEN, 2021.

Assim, o biogás tem se tornado como uma das opções mais sustentáveis, demonstrando tecnologia em estágio avançado de escalonamento industrial, e tem potencial para crescimento exponencial. O biogás evidencia excepcionais condições para diminuir tanto o metano orgânico quanto o $\mathrm{CO}_{2}$ lançado na atmosfera.

Sua produção envolve processos circunscritos, controlados e otimizados, de maneira comercialmente viável, gerando um biocombustível que pode ser utilizado tanto na geração de eletricidade quanto em veículos, em substituição ao diesel. Durante a combustão do biogás, o metano é transformado em $\mathrm{CO}_{2}$ e água, minimizando o impacto climático negativo e tornando, dessa forma, lucrativa a atividade de processar resíduos (Milanez et al., 2018).

Nesse contexto, a presente revisão bibliográfica teve como objetivo apresentar resultados de produção de biogás a partir de resíduos orgânicos, visto que os resíduos agroindustriais são responsáveis por três quartos do potencial de matérias-primas a serem exploradas para a produção do biogás.

As diversas atividades urbanas e rurais geram muitos resíduos os quais precisam ser tratados. Aliado a essa situação existe a necessidade de substituição do petróleo, o que se torna um processo essencial para a saúde pública e redução da poluição das águas (Marques, 2012).

Segundo a Associação Brasileira das Empresas de Limpeza Pública e Resíduos Especiais, o Brasil produz em torno de 37 milhões de toneladas de lixo orgânico, o qual tem grande potencial econômico para se transformar em adubo, gás combustível ou até mesmo energia. Entretanto, desse total descartado, somente $1 \%$ é reaproveitado (CBN, 2019).

O Ministério do Meio Ambiente e a Lei 12305/10 afirmam que os resíduos sólidos orgânicos e todo resíduo de origem animal ou vegetal possuem diferentes origens, tais como doméstica ou urbana (como restos de alimentos); agrícola ou industrial, tais como resíduos de indústrias alimentícias, madeiras e frigoríficas e resíduos provenientes do saneamento básico (lodos de estações de tratamento de esgotos), entre outros (Kretzer et al., 2016).

No procedimento de produção das refeições é tradicional o rejeite de materiais orgânicos que não estão aptos para o consumo, bem como as sobras dos pratos dos clientes, e os restos que foram preparados e não foram consumidos. Toda essa matéria orgânica geralmente é descartada em um aterro sanitário ou lixão, causando impacto ambiental no meio físico (Nascimento, 2014).

Assim, a matéria orgânica oriunda da agricultura apresenta grande potencial para a produção de biogás. Além disso, os resíduos de atividades agrícolas e os dejetos de animais também são de grande interesse para a geração de biogás (Karlsson et al., 2014).

O tratamento e descarte apropriado de resíduos orgânicos podem ser viabilizados através da utilização de biodigestores, em que os resíduos orgânicos são submetidos ao processo de biodigestão anaeróbia no interior do biodigestor, onde será degradado e ocorrerá a estabilização da matéria orgânica, modificando a estrutura bioquímica do resíduo, diminuindo microrganismos patogênicos, produzindo gases (biogás) como o metano e biofertilizantes (matéria orgânica estabilizada), gerando menos poluentes (Molino et al., 2013).

O processo de biodigestão ou fermentação anaeróbia é muito complexo e um grande número de espécies de bactérias, produtoras ou não de metano, auxiliam de certa forma para sua degradação (Tietz et al., 2014).

Tais microrganismos agem em conjunto com diversos fatores tais como: $\mathrm{pH}$, temperatura e tipo e composição de substrato, teor de água dos resíduos, tamanho das partículas, densidade dos resíduos, presença de nutrientes e a relação carbono e nitrogênio, os quais afetam a composição do biogás produzido. O processo de digestão anaeróbia, ou seja, a conversão da matéria orgânica em gases, passa por diversas etapas, quais podem ser visualizadas na Figura 3 (Karlsson et al., 2014). 

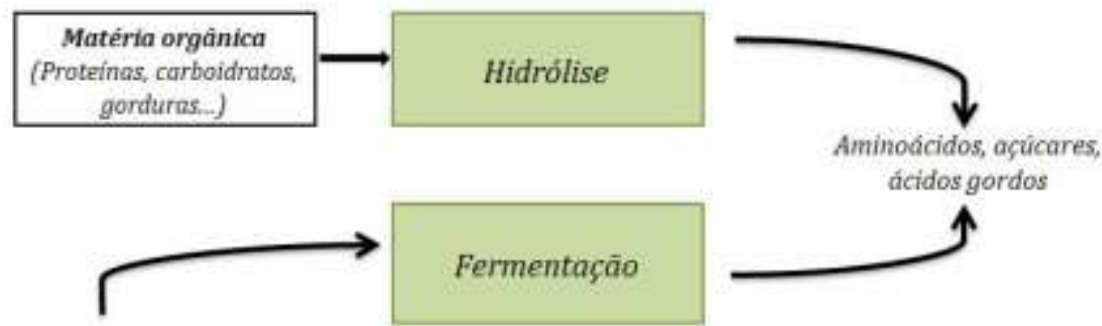

Amónia, álcoois, ácidos gordos, hidrogênio e dióxido de carbono
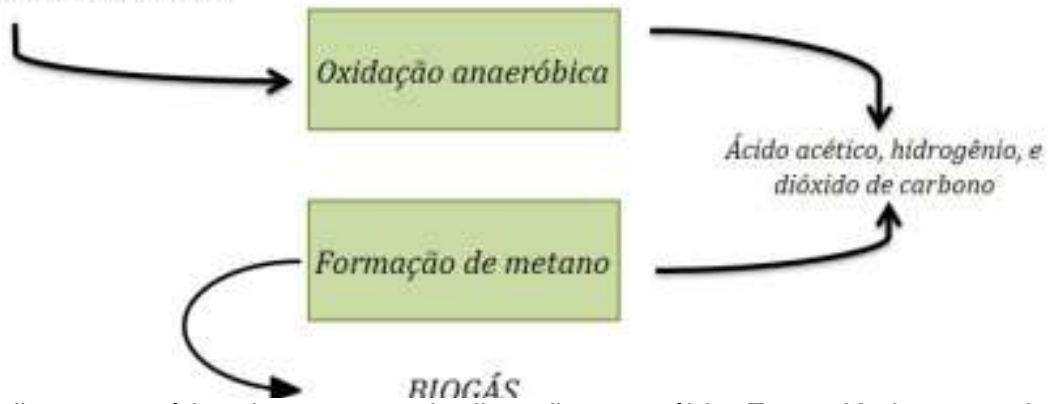

Figura 4. Representação esquemática do processo de digestão anaeróbia. Fonte: Karlsson et al. (2014).

No momento em que a ocorre a diminuição da carga orgânica presente em um resíduo, ocorre a redução do poder poluente e dos riscos sanitários desses dejetos e simultaneamente, tem-se como subproduto o biogás, o qual pode ser convertido em energia térmica ou elétrica e o biofertilizante utilizado como adubo (Steil et al., 2002).

Os primeiros países que produziram biogás e o utilizaram como fonte de energia foram a China e a Índia. $\mathrm{Na}$ época, eram utilizados restos de alimentos e dejetos em geral, como matéria-prima, sendo que o biogás produzido era usado para iluminação e cocção. Em meados de 1900, esses países começaram a aproveitar o processo de digestão anaeróbica para a geração de biogás focados nos lodos de esgoto (Karlsson et al., 2014).

O biogás é composto de 60 a $70 \%$ de metano $(\mathrm{CH} 4)$ e 30 a $40 \%$ de dióxido de carbono $\left(\mathrm{CO}_{2}\right)$, além de pequena quantidade de gás hidrogênio $\left(\mathrm{H}_{2}\right)$, gás nitrogênio $\left(\mathrm{N}_{2}\right)$ e gás sulfídrico $\left(\mathrm{H}_{2} \mathrm{~S}\right)$ (Sagula, 2012). O metano não apresenta cor e cheiro, sendo extremamente inflamável de chama azul lilás e não deixa fuligem (Barrera, 2003).

Uma das principais vantagens da digestão anaeróbia é a redução da poluição provocada pelo descarte de lixo, além de agregar o benefício da produção de biogás, usado como fonte de energia. Além disso, existe a produção do biofertilizante, o que faz com que o aproveitamento dos produtos oriundos desse processo seja quase completo (SILVA et al., 2005).

Kretzer et al. (2016) estudaram a utilização de resíduos orgânicos oriundos de um restaurante universitário, no processo de biodigestão anaeróbia em biodigestores de tamanho reduzido. Os autores verificaram que a alface e beterraba in natura apresentaram baixas reduções de carbono orgânico e produção de biogás nula, sendo essencial verificar a necessidade de pré-processamento para retirada de produtos que podem afetar a biodigestão. Já o arroz e o feijão apresentaram conteúdos de carbono orgânico e massa total reduzidos, sendo utilizados com sucesso na produção de biogás.

A viabilidade energética de produção de biogás foi verificada por Araújo (2017), ao estudar um modelo de implantação de biogás, utilizando os resíduos sólidos orgânicos oriundos do restaurante universitário da Universidade Federal de Uberlândia. O autor constatou o baixo custo de produção, bem como os benefícios ao meio ambiente, devido ao aproveitamento dos resíduos do restaurante. Assim, é uma proposta com elevado potencial de implantação, sobretudo devido às vantagens econômicas e sustentáveis provenientes do processo anaeróbico estudado.

Silva (2017) estudaram o processo de digestão anaeróbia a partir do lodo de esgoto e resíduos orgânicos, com foco na produção de biogás. Além disso, 0 autor acompanhou a instalação de biodigestores no Reserva Camará, localizado em Camaragibe (PE). $\mathrm{O}$ autor verificou que quanto à caracterização dos substratos, tanto o lodo da estação de tratamento quanto os resíduos de alimentos apresentaram características como $\mathrm{pH}$ semelhantes em amostras diferentes, o que garante a homogeneidade da alimentação dos biodigestores.

A produção de biogás produzida pela biodigestão anaeróbia dos resíduos orgânicos de um restaurante universitário, com adição de efluente doméstico e óleo de cozinha foi estudada por Nascimento (2014). Com base nos resultados obtidos, o autor verificou que a eficiência do processo de digestão depende do controle do $\mathrm{pH}$ e da alcalinidade do meio, visto que sua alteração pode causar a inibição do metabolismo dos microrganismos metanogênicos, dificultando a produção de biogás.

Outro resíduo orgânico que tem sido utilizado como substrato para a produção de biogás 
é o bagaço da laranja, visto que possui diversos polímeros de carboidratos solúveis e insolúveis que são a matéria-prima ideal para conversão em biocombustíveis biológicos, como etanol e biogás (Taghizadeh-Alisaraei et al., 2016). Assim, as cascas, bagaços e sementes de frutas podem ser usadas como biomassa para a obtenção de energia por métodos renováveis como a digestão anaeróbia, produzindo o biogás, o qual pode ser usado como fonte de energia direta, como queima em caldeiras, motogeradores e turbinas a biogás. Uma desvantagem quanto ao bagaço da laranja é o $\mathrm{pH}$ ácido (3-4) e o elevado teor de material lignocelulósico, o que pode dificultar o processo de digestão anaeróbia, caso não seja utilizado um inóculo aeróbio adequado (Santos et al., 2018).

Diante disso, Santos et al. (2018) verificaram a produção e o potencial de biogás e metano do bagaço de laranja empregando lodo industrial como inóculo na digestão anaeróbia e concluíram que a utilização do bagaço da laranja com lodo industrial foi eficiente quanto à produção, potencial de geração e porcentagem de metano.

\section{Considerações finais}

O processo de digestão anaeróbia pode ser uma alternativa ambiental viável para o tratamento de resíduos orgânicos, produzindo biogás e se tornando uma fonte de energia renovável. Entretanto, é um processo que exige condições específicas por envolver um sistema microbiológico, mas, se as condições operacionais forem otimizadas, faz com que o processo seja eficiente, com base nos estudos apresentados.

\section{Referências}

ARAÚJO, A. P. C. Produção de biogás a partir de resíduos orgânicos utilizando biodigestor anaeróbico. Monografia (Graduação em Engenharia Química) Universidade Federal de Uberlândia. 2017. 42 p.

BARRERA, P. Biodigestores: energia, fertilidade e saneamento para a zona rural. 2. Ed. São Paulo: Ícone, p.106, 2003.

BEN. Relatório Síntese 2021. Ano base 2020. Ministério de Minas e Energia. Disponível em: < https://www.epe.gov.br/pt/publicacoes-dadosabertos/publicacoes/balanco-energetico-nacional-2021>. Acesso em 10 out 2021.

CARVALHO, J. L. R.; MACHADO, M. N. M.; MEIRELLES, A. M. Mudanças climáticas e aquecimento global: implicações na gestão estratégica de empresas do setor siderúrgico de Minas Gerais. Cadernos EBAPE.BR, v. 9, n. 2, p. 220-244, 2011.

CBN. Apenas $1 \%$ do lixo orgânico é reaproveitado no Brasil. Disponível em: $<$ http://www.assemae.org.br/noticias/item/4494-apenas-1do-lixo-organico-e-reaproveitado-no-brasil>. Acesso em 12 out 2021.

CONCEIÇÃO, M. S.; MENDES, T. A.; MUNIZ, E. Conceitos básicos sobre mudança do clima: causas, mitigação e adaptação. (Monografia do BID; 326), 68p. 2015.

CYPRIANO, D. Z. Biomassa de casca de laranja industrial como fonte de bioetanol e produtos de alto valor agregado. Dissertação (Mestrado) - Universidade Estadual de Campinas, Instituto de Química, Campinas. 103 p. 2015.

KARLSSON, T.; KONRAD, O.; LUMI, M.; SCHMEIER, N. P.; MARDER, M.; CASARIL, C.A.; KOCK, F. F.; PEDROSO, A.G. Manual Básico de Biogás. 1 ed. Lajeado: Ed. da Univates, 2014. 69 p.

GALLO, J.M.R., BUENO, J.M.C., SCHUCHARDT., U., Catalytic transformations of ethanol for biorefineries, Journal of the Brazilian Chemical. Society, 2014.

KRETZE, S. G.; NAGAOKA, A. K.; MOREIRA, T. E.; MORAES, I. L. R. G.; BAUER, F. C. Produção de biogás com diferentes resíduos orgânicos de restaurante universitário. Revista Brasileira de Energias Renováveis, v.5, n.4, p.551-565, 2016.

MARQUES, C. A. Microgeração de energia elétrica em uma propriedade rural utilizando biogás como fonte primária de energia elétrica. Dissertação (Mestrado em Energia na Agricultura) - Universidade Estadual do Oeste do Paraná, Paraná. 81 p. 2012.

MILANEZ, A. Y.; GUIMARAES, D. D.; MAIA, G. B. S.; SOUZA, J. A. P.; LEMOS, M. L. F. Biogás de resíduos agroindustriais: panorama e perspectivas. BNDES Setorial, Rio de Janeiro, n. 47, p. 221-275, 2018.

MOLINO A.; NANNA, F.; DING, Y.; BISKON, B.; BRACCIO, G. Biomethane production by anaerobic digestion of organic waste. Fuel, v. 103, p. 1003-1009, 2013.

NASCIMENTO, R. C. Biogás de resíduos orgânicos do restaurante universitário com adição de efluente doméstico e óleo de cozinha. Trabalho de Conclusão de Curso (Engenharia Ambiental) - Universidade Tecnológica Federal do Paraná, Londrina. 2014. 43 p.

SAGULA, A. L. Biodigestão anaeróbia de cama de frango em co-biodigestão com caldo de cana-de-açúcar. Dissertação (Mestrado em Energia na Agricultura) Universidade Estadual Paulista, Botucatu, p. 69, 2012.

SANTOS, H. S. Mudanças Climáticas. Disponível em: $<$ https://www.biologianet.com/ecologia/mudancasclimaticas.htm>. Acesso em 15 set 2021.

STEIL, L.; LUCAS JUNIOR, J.; OLIVEIRA, R.A. Avaliação do uso de inóculos na digestão anaeróbia de resíduos de aves de postura, frango de corte e suínos. Journal of the Brazilian society of Agricultural Engineering, v.22, n.2, p. 146-149, 2002.

TAGHIZADEH-ALISARAEIA, A.; HOSSEINIA, S. H.; GHOBADIANB, B.; MOTEVALIC, A. Biofuel production from citrus wastes: A feasibility study in Iran. Renewable and Sustainable Energy, v. 69, p. 1100-1112, 2017.

TIETZ, C. M.; ZENATTI, D. C.; FEIDEN, A.; LUPATINI, K. $\mathrm{N}$. Influência da temperatura na produção de biogás a partir de dejetos da bovinocultura de leite. Revista 
Brasileira de Energias Renováveis, v. 3, n. 5, p.80-96,

2014.

VÁSQUEZ, J. E.; QUINTERO, J. C.; OCHOA-CÁCERES,

S. Modeling of a simultaneous saccharification and fermentation process for ethanol production from

lignocellulosic wastes by kluyveromyces marxianus,

DYNA, 2014. 